\title{
Regional Differences in Antifungal Susceptibility of the Prevalent Dermatophyte Trichophyton rubrum
}

\author{
Y. Jiang $\cdot$ W. Luo $\cdot$ P. E. Verweij $\cdot$ Y. Song $\cdot$ B. Zhang $\cdot$ Z. Shang $\cdot$ \\ A. M. S. Al-Hatmi - S. A. Ahmed • Z. Wan • R. Li • G. S. de Hoog
}

Received: 5 September 2020/Accepted: 25 November 2020/Published online: 12 December 2020

(C) The Author(s) 2020

\begin{abstract}
In vitro susceptibility testing for Trichophyton rubrum has shown resistance to terbinafine, azoles and amorolfine, locally, but epidemiological cutoffs are not available. In order to assess the appropriateness of current first-line antifungal treatment for $T$. rubrum in China, we characterized antifungal susceptibility patterns of Chinese T. rubrum strains to nine antifungals and also described the upper limits of wild-type (WT) minimal inhibitory concentrations (MIC) (UL-WT) based on our study and
\end{abstract}

Handling Editor: Hamid Badali

Yanping Jiang and Wanglan Luo have contributed equally to this work.

Supplementary Information The online version of this article (https://doi.org/10.1007/s11046-020-00515-z) contains supplementary material, which is available to authorized users.

Y. Jiang - W. Luo

Department of Dermatology, The Affiliated Hospital,

Guizhou Medical University, Guiyang, China

Y. Jiang · P. E. Verweij · A. M. S. Al-Hatmi .

S. A. Ahmed · G. S. de Hoog

Department of Medical Microbiology, Radboud

University Medical Center, Center of Expertise in

Mycology Radboudumc/CWZ, Nijmegen, The

Netherlands another six studies published during the last decades. Sixty-two clinical isolates originating from seven provinces in China were identified as T. rubrum sensu stricto; all Chinese strains showed low MICs to eight out of nine antifungal drugs. Terbinafine (TBF) showed the lowest MICs of all antifungal classes tested in both the Chinese and global groups, with a 97.5\% UL-WT MIC-value of $0.03 \mathrm{mg} / \mathrm{L}$. No non-WT isolates were observed for TBF in China, but were reported in $18.5 \%$ of the global group. Our study indicated that TBF was still the most active drug for Chinese T. rubrum isolates, and all strains were within the WT-population. TBF therefore remains recommended for primary therapy to dermatophytosis caused by $T$. rubrum in China now, but regular surveillance of dermatophytes and antifungal susceptibility is recommended.

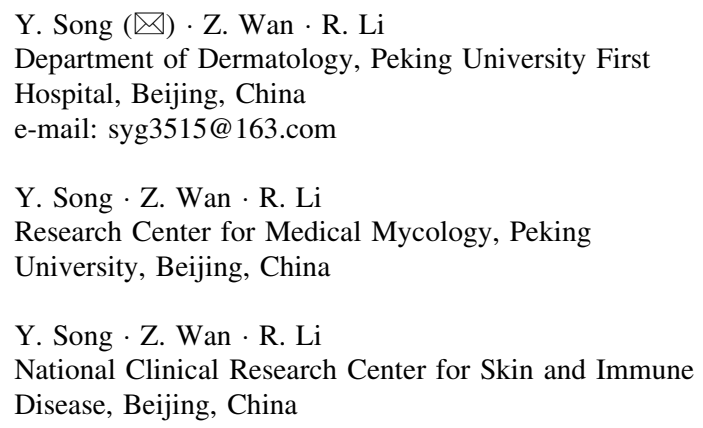


Keywords Dermatology - Antifungal agents - Drug resistance $\cdot$ Terbinafine $\cdot$ Trichophyton

\section{Introduction}

Trichophyton rubrum has been among the most prevalent dermatophytes causing tinea pedis and tinea unguium since the early twenty-first century [1]. The global predominance of $T$. rubrum suggests that this species has a significantly higher capacity of transmission than other anthropophilic dermatophytes [2]. Numerous authors have noted, as confirmed by wholegenome sequencing [3], that T. rubrum is clonal with a highly conserved gene content, low levels of variation, and little evidence of recombination. On the Indian subcontinent, the species is still common [4-6], but seems gradually to be replaced by members of the $T$. mentagrophytes group [4, 5, 7], thus having a similar fate as the classical, disappearing dermatophytes Epidermophyton floccosum and Microsporum audouinii [1]. One of the main characteristics promoting global spread is the low virulence of T. rubrum [8]. Its mild, hardly noticeable cutaneous infections with transmission via skin scales released from mild hyperkeratosis does not interfere with transmissionenhancing interaction of human hosts. Infections only are more serious in CARD9-deficient patients or in those with dysfunctional cellular immunity, e.g., with cirrhosis, AIDS, hematological malignancies or solid organ transplants [9-11].

Acquired resistance, as observed in numerous fungi, is however a concern. T. rubrum is regarded to have limited capacity to develop resistance to

\section{B. Zhang}

School of Public Health, Guizhou Medical University, Guiyang, China

\section{Z. Shang}

Department of Immunology, Basic Medical School, Guizhou Medical University, Guiyang, China

\section{S. A. Ahmed}

Faculty of Medical Laboratory Sciences, University of Khartoum, Khartoum, Sudan

\section{A. M. S. Al-Hatmi}

Ministry of Health, Directorate General of Health

Services, Ibri, Oman terbinafine even after prolonged exposure [12], but it has been proven that $T$. rubrum can develop resistance to azoles, amorolfine and terbinafine after prolonged exposure to sub-inhibitory concentrations of these drugs [13-18]. Antifungal drug resistance may contribute to treatment failure and lead to persistent and chronic infections [13, 14]. The first report on $T$. rubrum exhibiting resistance to terbinafine was published in 2003 [15], followed by reports from the Americas, Europe and Asia [16-18]. Ebert et al. [19] indicated that resistance of $T$. rubrum for terbinafine was as high as $44 \%$, although lower than that of $T$. mentagrophytes group in India. This study also showed that the systemic antifungal drug terbinafine, first-line drug for dermatophytosis, had lost its in vitro activity in most parts in India [19].

It has been speculated that the resistance in dermatophytes might be related to drug exposure $[5,19]$. The management of over-the-counter drug use in China is similar to that in India, but resistance of $T$. rubrum has not systematically been reported from China. No clinical break points (CBP) or epidemiological cutoffs (ECV) are available to guide antifungal treatment and classify resistance in $T$. rubrum. The Guizhou Province, located in the southwest of China, is humid and mountainous, with poor transportation and backward economy. Local people and even doctors in basic hospitals pay insufficient attention to dermatophytosis and have poor awareness of diagnosis and treatment, whether it will lead to difference in drug susceptibility of $T$. rubrum in Guizhou region? Based on that, we compared clinical isolates from Guizhou Province with six regions in China in terms of genomic diversity of strains and in vitro susceptibility to a panel of antifungal drugs. In order to investigate potential trends in drug resistance of T. rubrum, we also reviewed available MIC values from published literature and describe wild-type (WT) MIC distributions of nine drugs for T. rubrum according to the criteria used by CLSI.

\section{Materials and Methods}

\section{Strains}

Sixty-two clinical $T$. rubrum strains from seven provinces in China were available for testing; geographic and clinical data are given in supplementary 
Table S-1. Thirty-one isolates cultured from tinea pedis were obtained from the Research Center for Medical Mycology at Peking University: five originated from Guangzhou, Sichuan, Ningxia, Wuhan and Jilin, respectively, and six from Xinjiang. Another 31 clinical isolates were obtained from the Department of Dermatology of Guizhou Medical University of China; of these, five were isolated from tinea pedis, and six others from tinea cruris, tinea corporis, tinea capitis, tinea faciei and tinea manuum, respectively; the remaining 20 strains were from tinea unguium. All strains were isolated during the period 2016-2019.

\section{Identification}

Identification of isolates was done by phenotype [20] and confirmed by rDNA internal transcribed spacer regions (ITS) sequencing. Briefly, isolates were subcultured on Sabouraud's Glucose Agar (SGA, homemade) incubated at $28{ }^{\circ} \mathrm{C}$ for one week. DNA extraction was by the cetyltrimethylammonium bromide (CTAB) method [21]. ITS of the rDNA operon was amplified with primers ITS5 and ITS4 according to in Jiang et al. [21, 22]. PCR products were sequenced by TSINGKE Biological Technology (Beijing, China). GenBank accession numbers for new sequences are given in supplementary Table S-1. For global comparison, 87 reference sequences were retrieved from GenBank, including $T$. rubrum $(n=76), \quad T$. violaceum $(n=4), \quad T$. soudanense $(n=4)$, with $T$. verrucosum $(n=3)$ as outgroup. Alignment was done with MUSCLE using MEGA v6.0 [23], and Bayesian inference analyses (BI) were performed using MRBAYES v3.1.2 [24].

\section{Antifungal Susceptibility}

A panel of nine commonly used topical or systemic antifungal agents (abbreviations according to de Hoog et al. [20]) were tested by the broth microdilution technique of Clinical and Laboratory Standards Institute (CLSI) protocol M38-A3 [25], as follows: luliconazole (LLCZ; Higher Biotech Co, Shanghai, China), amorolfine (AMF; Sigma Aldrich, St. Louis, USA), terbinafine (TBF; CFDA Co., Beijing, China), itraconazole (ITZ; CFDA), bifonazole (BFZ; CFDA), ketoconazole (KTZ; CFDA), miconazole (MCZ; CFDA), fluconazole (FCZ; Sigma Aldrich) and naftifine (NAF; CFDA). Stock solutions of all drugs were prepared in dimethyl sulfoxide (DMSO) at a concentration of $2 \mathrm{mg} / \mathrm{mL}$ (except FCZ, which was dissolved in distilled water at final concentration $102.4 \mathrm{mg} / \mathrm{mL}$ ). Drug stock solutions were diluted in RPMI 1640 medium buffered with 3-N-(morpholino)propanesulfonic acid (MOPS), in twice the final concentration followed by addition of equal volumes of the pre-adjusted inoculum of fungal isolates, in 96-well microtiter plates. Final concentrations of the antifungals tested ranged from 0.125 to $64 \mu \mathrm{g} / \mathrm{mL}$ for FCZ, 0.0078 to $4 \mu \mathrm{g} / \mathrm{mL}$ for KTZ, 0.004 to $2 \mu \mathrm{g} / \mathrm{mL}$ for BFZ, 0.002 to $1 \mu \mathrm{g} / \mathrm{mL}$ for ITZ, MCZ and AMF, 0.00025 to $0.125 \mu \mathrm{g} / \mathrm{mL}$ for TBF, 0.001 to $0.5 \mu \mathrm{g} / \mathrm{mL}$ for NAF and LLCZ. Drug plates were stored at $-70{ }^{\circ} \mathrm{C}$.

\section{Inoculum and Quantification}

Strains were subcultured from primary SGA plates to potato dextrose agar (PDA) to induce conidiation. Plates were incubated at $28{ }^{\circ} \mathrm{C}$ for $9-14$ days. Conidia were collected by gently flushing $5 \mathrm{~mL}$ phosphate buffer saline ( $\mathrm{pH}=7.4$ ) on colonies and aspirating the suspension into a sterile collection tube. Suspensions were counted on a hemocytometer and diluted in RPMI 1640 to the desired concentration of $1 \times 10^{3} \sim 3 \times 10^{3} \mathrm{CFU} / \mathrm{mL}$.

Reading of Results

Microdilution plates were incubated at $35{ }^{\circ} \mathrm{C}$ and visually read after 5-7 days. Endpoint MICs for azoles and TBF were considered when prominent inhibition (approximately 80\%) was reached compared to the control wells, while for NAF and AMF $100 \%$ growth inhibition was required. Ranges and geometric means (GMs) of the MICs were determined for each group and drug after 6 days. If no growth was observed or growth was inadequate, incubation was extended to 7 days. Candida parapsilosis (ATCC 22019) and $T$. mentagrophytes (ATCC MYA 4439) were included as quality control strains. All experiments were performed using two independent replicates on different days.

\section{Statistics}

Statistical analysis was performed by Mann-Whitney $U$ and Kruskal-Wallis tests (Student's $t$ test) using 
SPSS software v21. One-way analysis of variance (ANOVA) was used to compare the geometric mean (GM) MICs between the groups and within distinct geographic areas. $P$ values of $<0.05$ were considered significant. ECV values were computed by the Microsoft Excel spreadsheet calculator ECOFFinder XL 2010 v2.1 (https://clsi.org/), which follows a methodology established by Turnidge et al. [26]

\section{Literature Search}

Keywords "Dermatophytes", "Trichophyton rubrum", "Antifungal susceptibility", "Resistance", "Minimum inhibitory concentration" and "Geometric mean (GM)" were used in a PubMed and CNKI (China National Knowledge Infrastructure) to screen English and Chinese literature for research articles and reviews published from 2010 to 2020. In addition, CLSI M38-A2 broth microdilution protocol was considered as a restrictive condition for literature review.

\section{Results}

Identification

T. rubrum is reliably identified by the rDNA ITS barcoding marker [27, 28]. Phylogenetic analysis resolves species boundaries between the closely related siblings in the T. rubrum complex (Fig. 1). In the alignment (555 bp including gaps), three groups differing by single nucleotide polymorphisms (SNPs) were revealed. Group 1 (T. rubrum sensu stricto) comprised two clusters matching with Haplotypes 5 and 6 [27]. H5 comprised 134 identical isolates and included the neotype strain CBS 392.58 (Group 1A). All strains from our study clustered into this subclade and revealed $100 \%$ sequence similarity. Five strains (Group 1B), one of which was from China, deviated by a single SNP matching haplotype H6 [27]. Two remaining clusters in the $T$. rubrum complex contained reference strains of $T$. violaceum (Group 2, $7 \mathrm{bp}$ distance) and T. soudanense (Group 3, 4 bp distance).

Antifungal Susceptibility

MIC ranges, geometric means (GMs) of MICs and MIC50/MIC90 ratios were obtained for nine antifungals and 62 isolates applying the CLSI protocol (Table 1, Fig. 2a). Among nine drugs, TBF was the most active antifungal drug against all $T$. rubrum strains, with lowest MICs $(\mathrm{GM}=0.00688 \mu \mathrm{g} / \mathrm{mL}$, MIC50 $=0.008 \mu \mathrm{g} / \mathrm{mL}, \quad$ MIC90 $=0.015 \mu \mathrm{g} / \mathrm{mL}$; $P<0.01)$. LLCZ also was active with low MIC values $(\mathrm{GM}=0.0169 \mu \mathrm{g} / \mathrm{mL}, \quad$ MIC50 $=0.015 \mu \mathrm{g} /$ $\mathrm{mL}$, MIC90 $=0.06 \mu \mathrm{g} / \mathrm{mL}$ ), but the difference with NAF and MCZ was not statistically significant $(P>0.05)$.

The nine drugs belong to four categories, and MIC values were compared in the $62 \mathrm{~T}$. rubrum strains accordingly. Significant differences between antifungal classes were observed (Fig. 2b). Azoles were divided into a topical and a systemic category, respectively. The systemic azoles included KTZ, ITZ and FCZ, while the topical azoles included LLCZ, BFZ and MCZ. MIC values of the systemic azoles were significantly higher than those of the topically administered compounds (GM 0.2236 vs. $0.03245 \mu \mathrm{g} / \mathrm{mL} ; P<0.001)$. Allylamines, including TBF and NAF, which can be used systemically or topically, were associated with lowest MICs $(P<0.001)$. The morpholine derivatives included the single drug AMF, which is used only topically. AMF was active against all T. rubrum strains with low MICs, GMs being just slightly higher than that of the topical azole category (GM: 0.05271 vs. $0.03245 \mu \mathrm{g} /$ $\mathrm{mL}, P<0.05)$.

For a third comparison of MIC values, we separated the T. rubrum strains geographically, i.e., a Guizhou group and those from remaining Chinese provinces. There was no difference in drug susceptibility between the two groups for the eight drugs; only for AMF, the 31 strains from Guizhou showed slightly higher MIC values than those from remaining China (GM MIC values: 0.059 vs. $0.047 \mu \mathrm{g} / \mathrm{mL}, P<0.05$ ) (Fig. $2 \mathrm{C}$ ).

\section{Literature Review and UL-WT Determination}

We subsequently compared published susceptibility data (MIC range and GM) of T. rubrum for the nine drugs during the last decade (Table 2, Figs. 3, 4). Since the year 2000, a total of 26 AFST studies comprising 1153 isolates have been carried out with the CLSI M38A2 protocol [29], including 7 in China [30-35]; 9 in India; 6 in Iran; and one each in the USA., Germany, Brazil and Japan [6, 18, 19, 36-50]. The number of $T$. rubrum strains included in the 


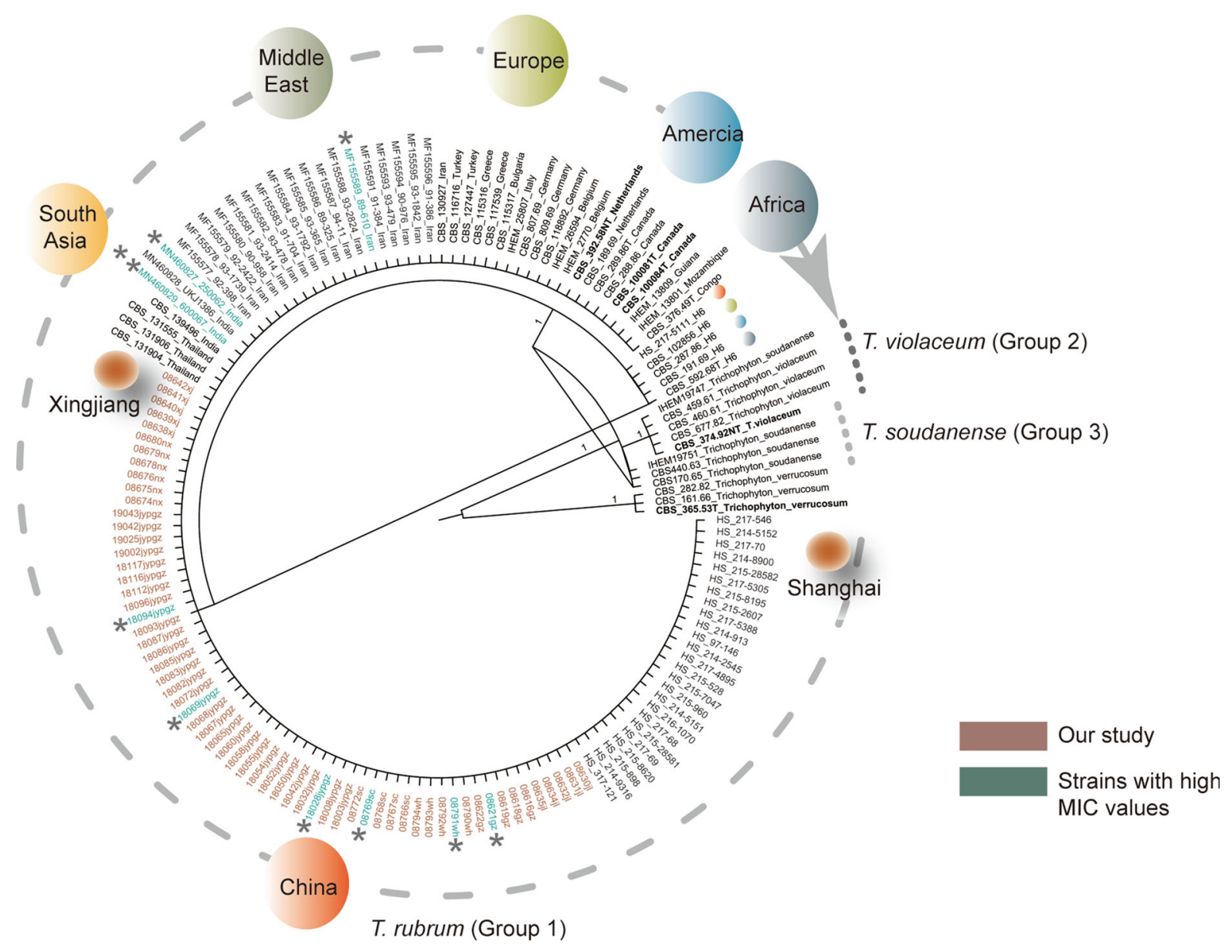

Fig. 1 Single-locus representation of ITS sequences in Trichophyton rubrum complex. Bootstrap (BPP > 0.95) from BI analyses is shown along the branches. T. rubrum monophyletic clades (Group 1) are color-coded according to

studies ranged from 5 to 308 ; inoculum sizes ranged from $10^{3}$ to $10^{4} \mathrm{CFU} / \mathrm{mL}$; most studies $(13 / 26)$ incubated at $35{ }^{\circ} \mathrm{C}$ for a period of 4-7 days. Twenty studies were published during the last five years, with the most frequently studied drugs being ITZ, FCZ, KTZ and TBF. In 26 studies, the largest disparity in GM MIC values was observed with $\mathrm{TBF}$, values differing in nine dilution steps $(0.004-2 \mu \mathrm{g} / \mathrm{mL}$; Figs. 3g, 4g), followed by ITZ (equal to 6 dilution steps, 0.03-3.0 $\mu \mathrm{g} / \mathrm{mL}$; Figs. 3f, 4f). For FCZ, a high GM averaged over all studies was noted $(4.56 \mu \mathrm{g} / \mathrm{mL})$, with a maximum disparity of 5 dilution steps (0.96-25.99 $\mu \mathrm{g} / \mathrm{mL}$; Fig. 3e). Only TBF showed a non-normal distribution, representing India's spheres geographic region. Trees are rooted with $T$. verrucosum. The strains in this study are marked in red, and the strains with high MIC values for FCZ or ITZ or TBF are marked in blue. Asterisks represent numbers of insensitive drugs. (Color figure online)

(2019) deviating significantly from the others (Fig. 3g).

In addition to our own data, six published studies presented the distribution of MICs values for nine antifungal drugs against $T$. rubrum, including two studies form China, three studies from India and one from Iran. We compared to the upper limit of wildtype MIC (UL-WT) distribution of T. rubrum between China and the global data set (Table 3). The number of strains tested exceeded 100 for KTZ, ITZ and TBF. Global data were not available for BFZ, MCZ, NAF and AMF. Both the $95 \%$ and $97.5 \%$ MICs were calculated to determine the wild-type MIC (UL-WT). For the antifungals which showed a multimodal, nonsymmetrical or truncated MIC frequency distribution, 


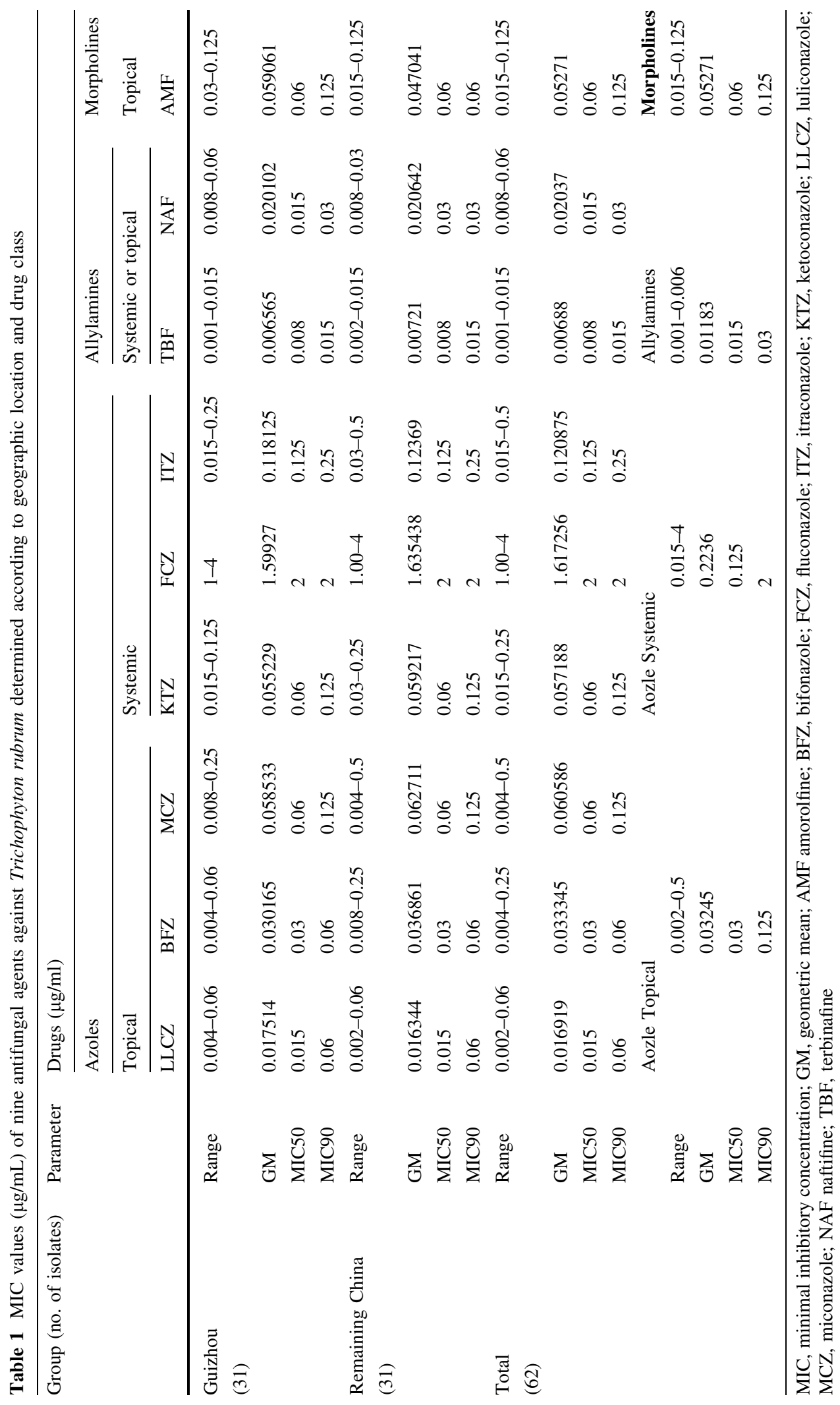




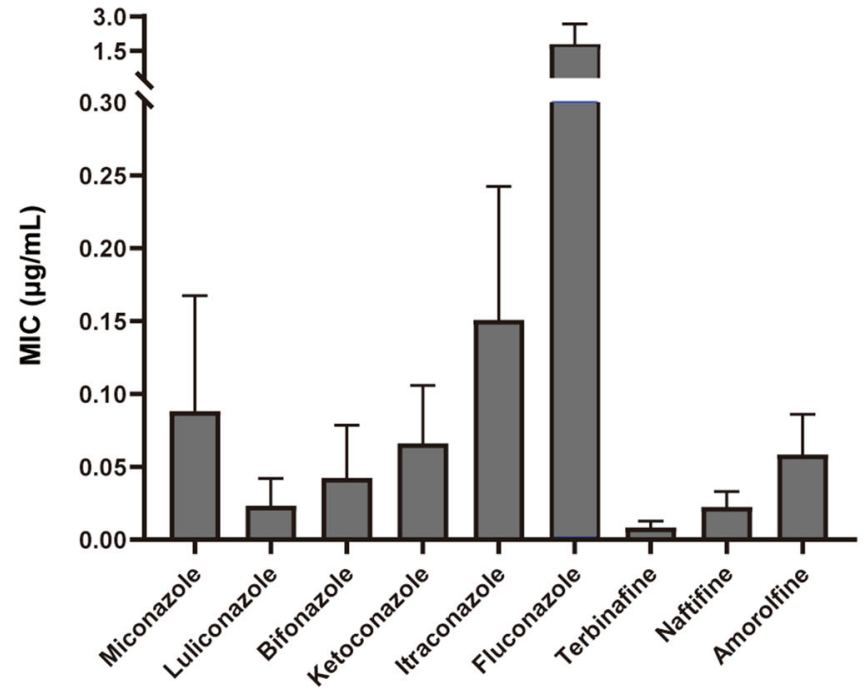

(A)

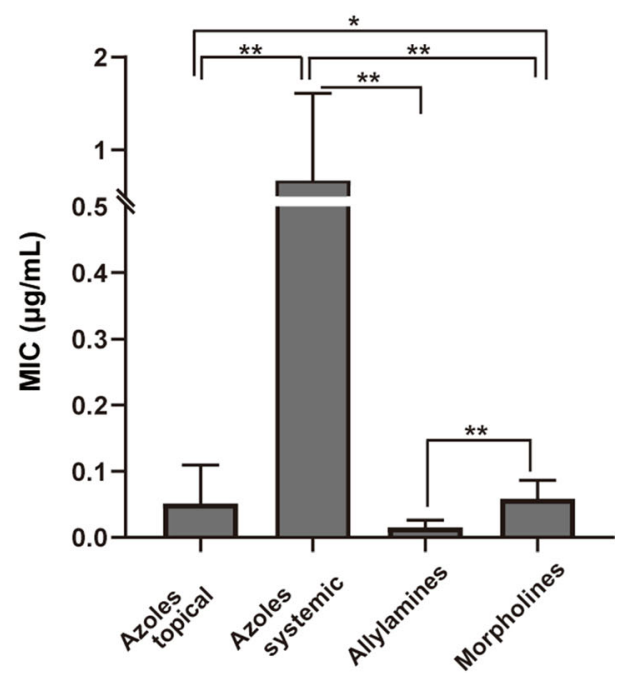

(B)

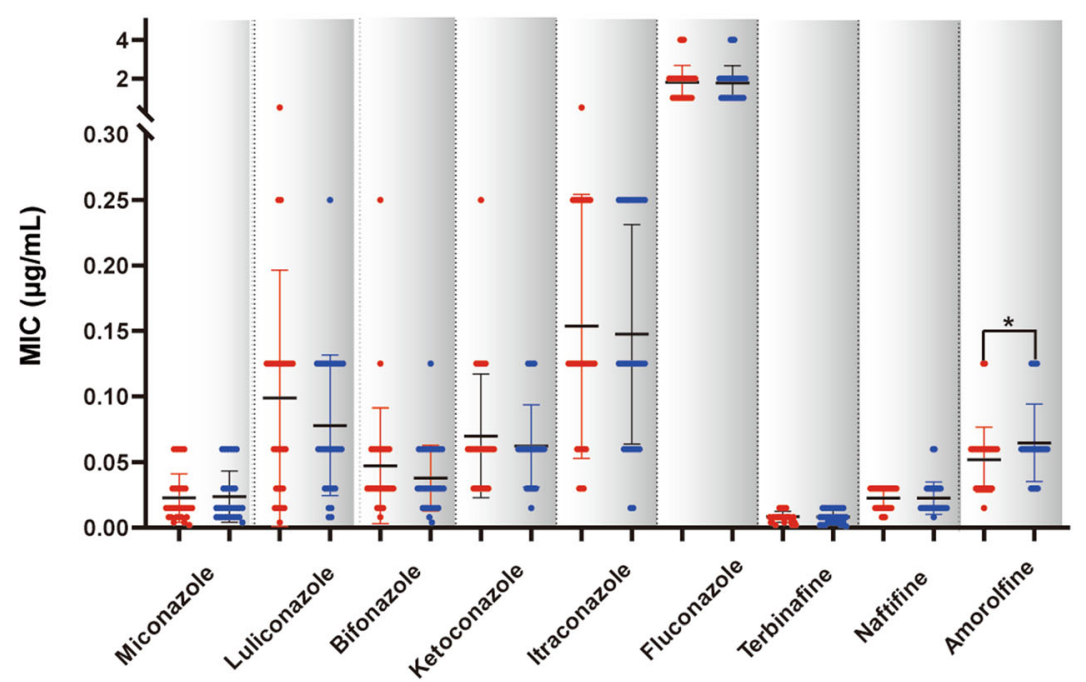

Remaining China group

Guizhou group

(C)

Fig. 2 Comparison of MIC values of 62 T. rubrum strains. (A) Box plot of nine antifungals tested. (B) Comparison of four categories of drugs. (C) Comparison of Guizhou group (red) with remaining China group (blue). $* *(P<0.01)$, $*(P<0.05)$. (Color figure online)

the MIC95 and MIC97.5 were documented as ULWT. Highest 97.5\% UL-WT were observed for FCZ $(8 \mathrm{mg} / \mathrm{L})$, whereas lowest value of $0.03 \mathrm{mg} / \mathrm{L}$ was found for TBF. The MICs comprising $>97.5 \%$ of the model populations were the same in both groups, as follows: 0.0312 for TBF; 0.0625 for NAF and LLCZ; 0.125 for BFZ; 0.25 for KTZ and AMF; 0.5 for MCZ and ITZ; 8 for FCZ. Highest percentage of isolates above the upper limit of wild-type MIC (UL-WT) were observed for KTZ (global: 34.2\%; China: $38.6 \%$ ). Low percentages of isolates above UL-WT were observed for LLCZ (global: $3.3 \%$; China: $3.7 \%$ ) and BFZ (global: $3.3 \%$; China: $3.7 \%$ ). The populations of non-WT strains for TBF, global group and Chinese group, were significantly different, with the former up to $18.5 \%$ and the latter none. The percentages of isolates above UL-WT for ITZ in the two groups was low (global: $3.2 \%$; China: 0 ). 


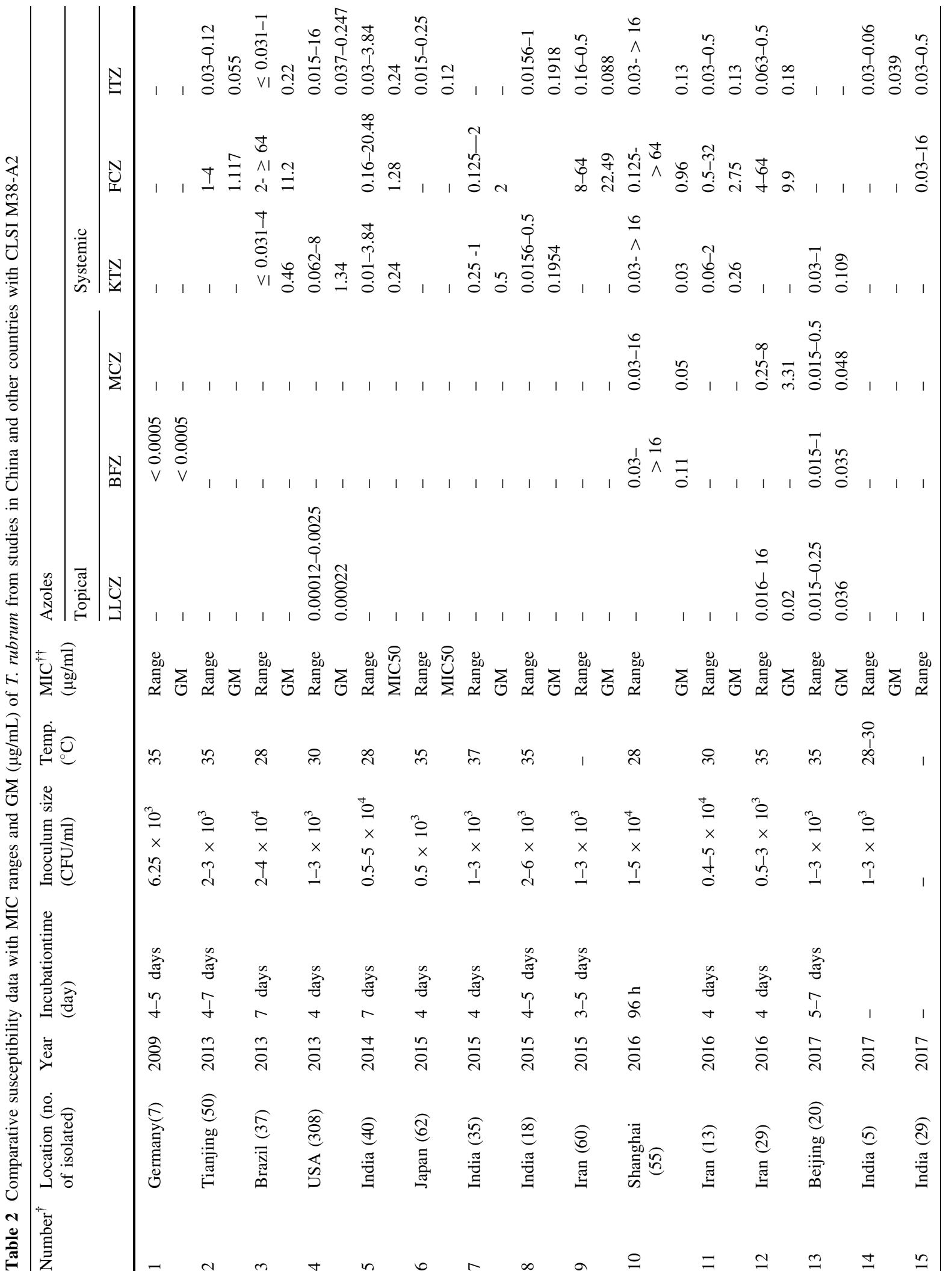




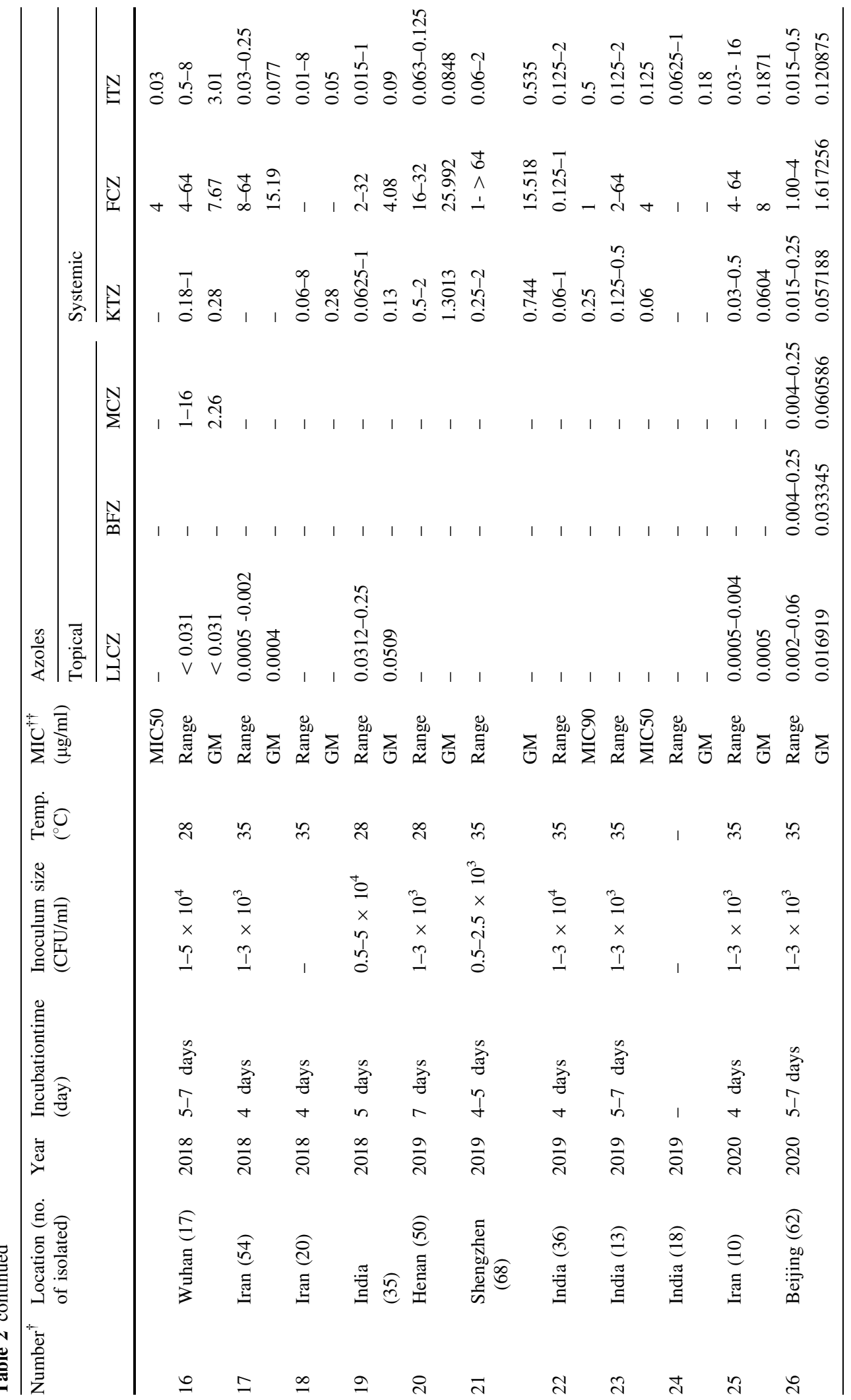




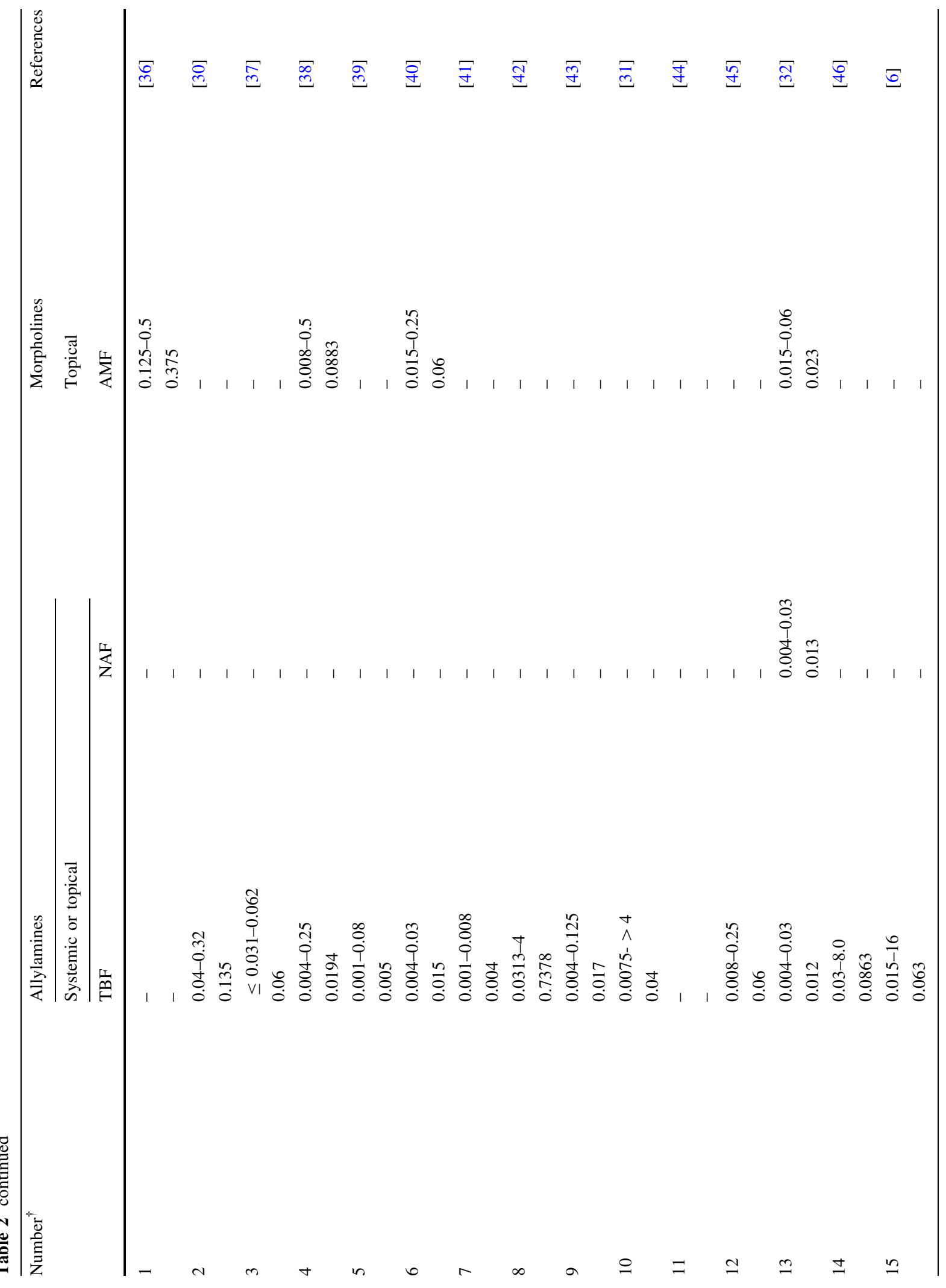




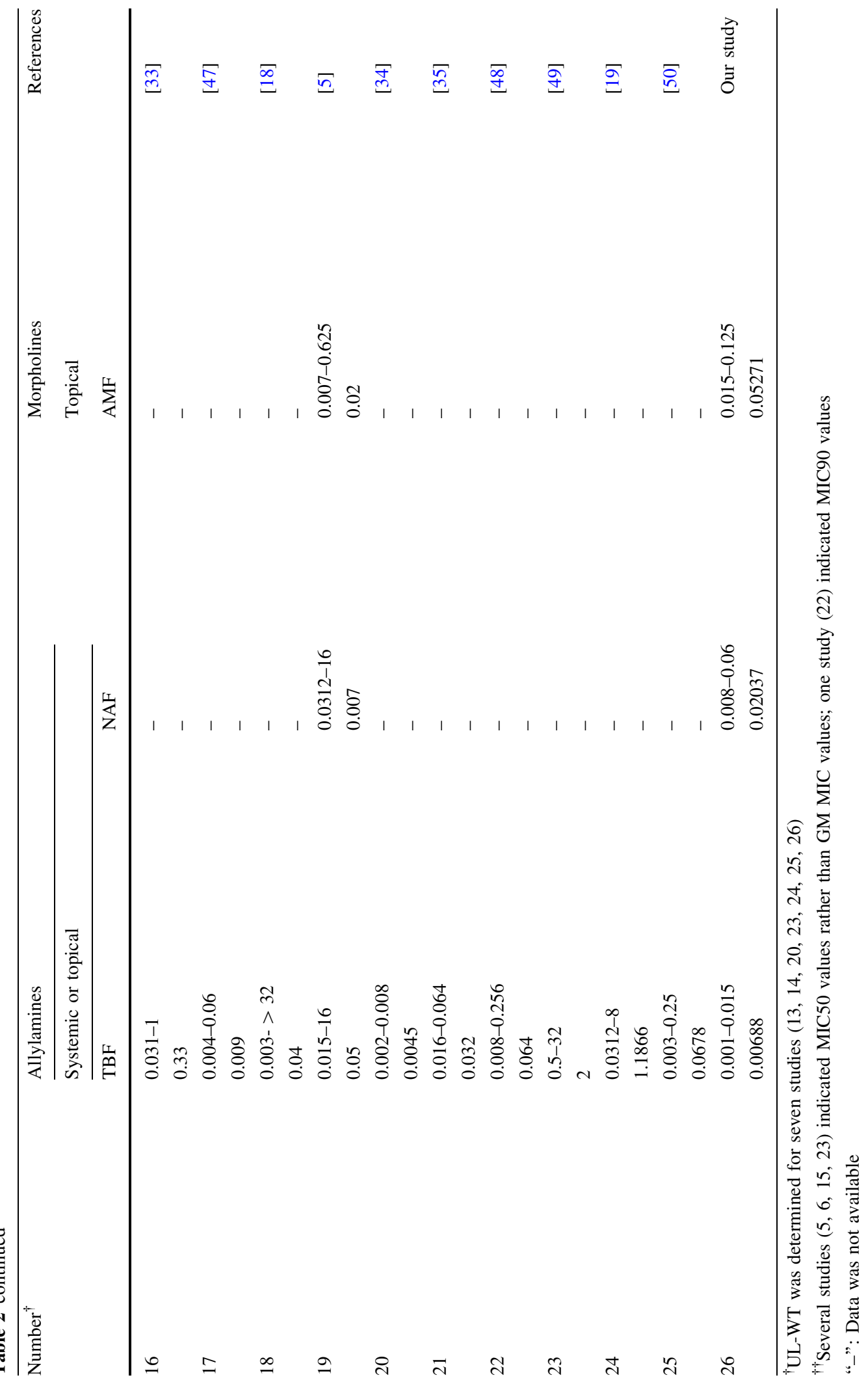




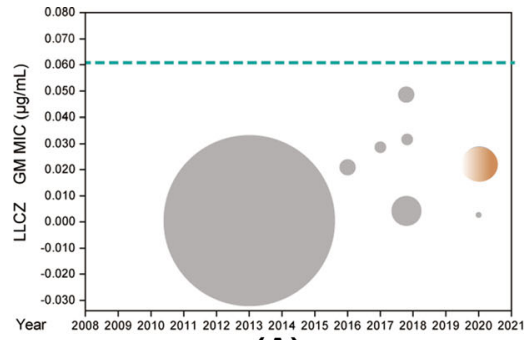

(A)

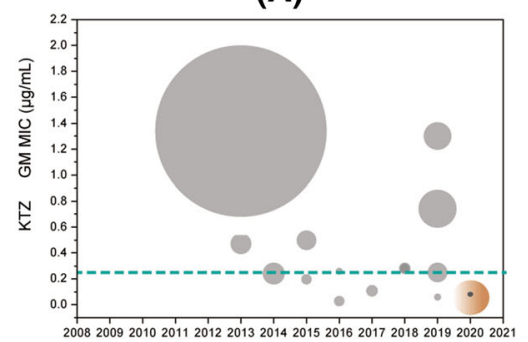

(D)

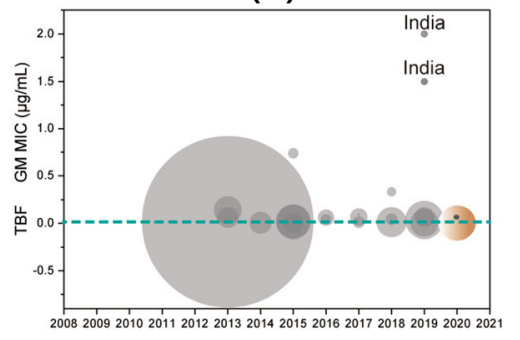

(G)

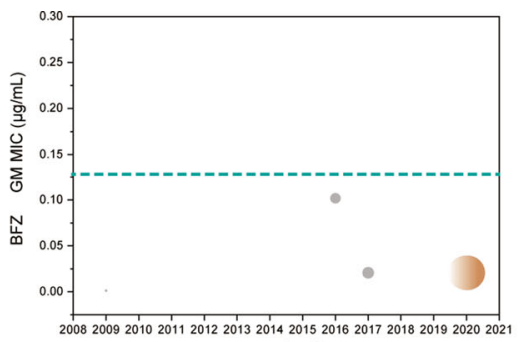

(B)

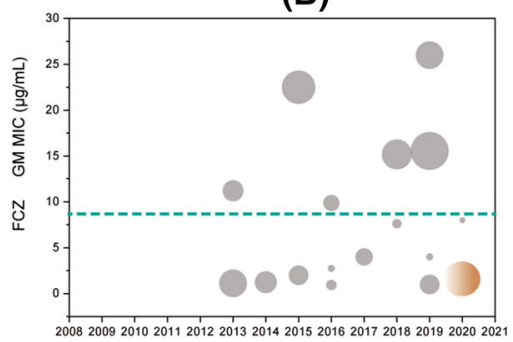

(E)

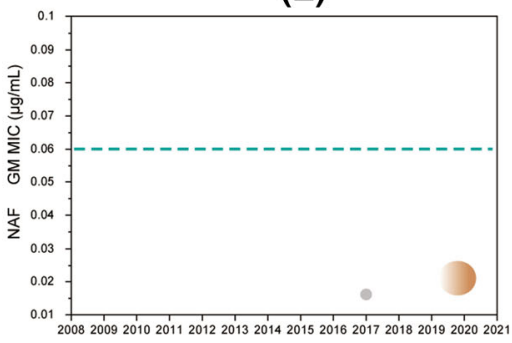

(H)

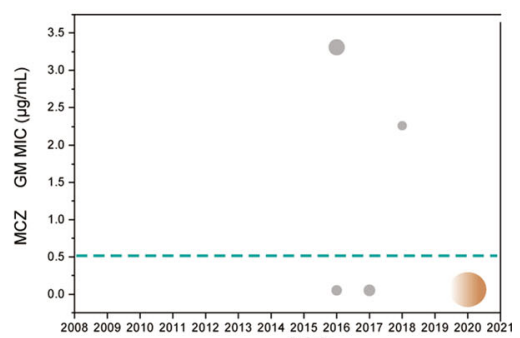

(C)

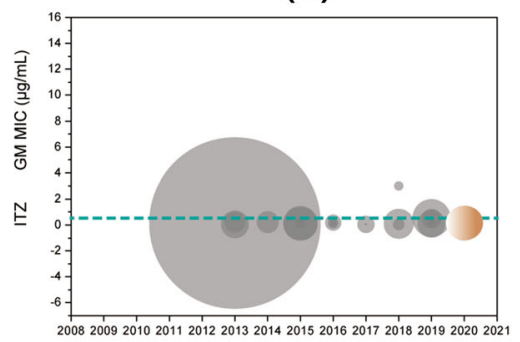

(F)

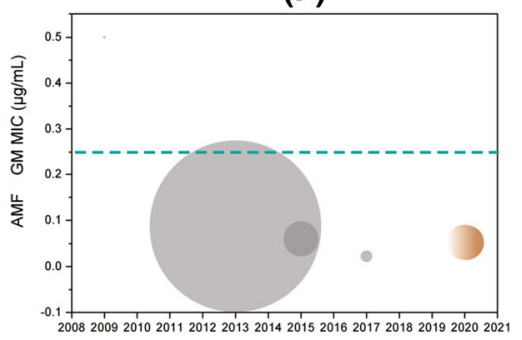

(I)

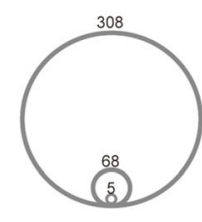

Number of study
Our study
Fig. 3 Comparison of MIC values for nine antifungal drugs in T. rubrum strains from 2010 to 2020. (A-I). LLCZ, BFZ, MCZ, KTZ, ITZ, TBF, NAF, AMF. The circle represents each study,

\section{Discussion}

Dermatophyte infections have received renewed interest during the last five years because of the emergence of recalcitrant, highly virulent species in South Asia $[19,51]$. The causative species was recently described as $T$. indotineae (T. mentagrophytes group) [52]. Given the rapid spread of dermatophytes, the potential replacement of mild $T$. rubrum by virulent $T$. and the center of the circle corresponds to the GM value; our study is highlighted in red. The blue line represents UL-WT MIC values for every drug. (Color figure online)

mentagrophytes group is a significant public health risk. In China, T. rubrum is still the predominant species among dermatophytes, similar to previously published data [1,3]. Antifungal resistance has also been reported in T. rubrum [16-19] and thus, a potential public health problem is apparent.

T. rubrum is identified phenotypically in the routine laboratory. For confirmation of identity, the rDNA internal transcribed spacer (ITS) barcoding gene is 


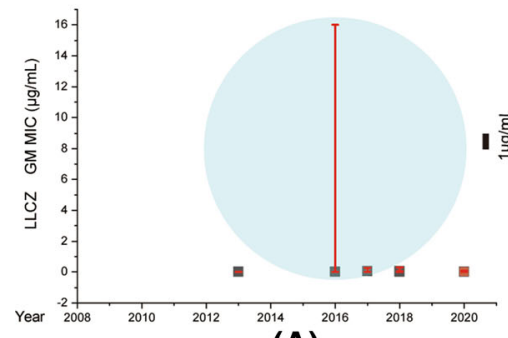

(A)

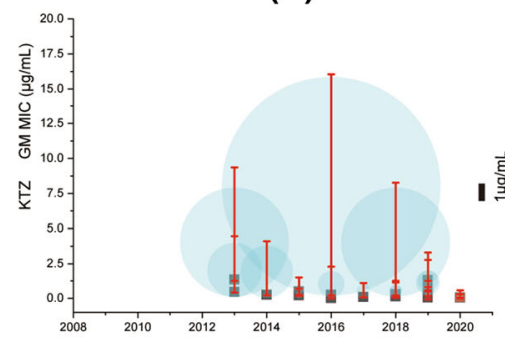

(D)

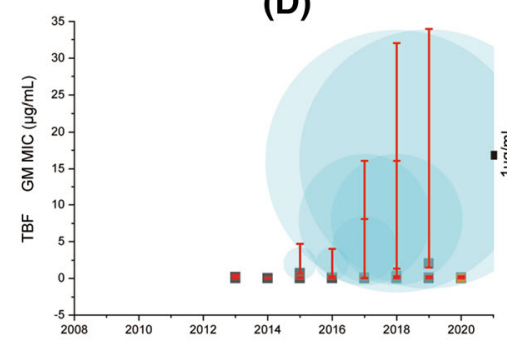

(G)

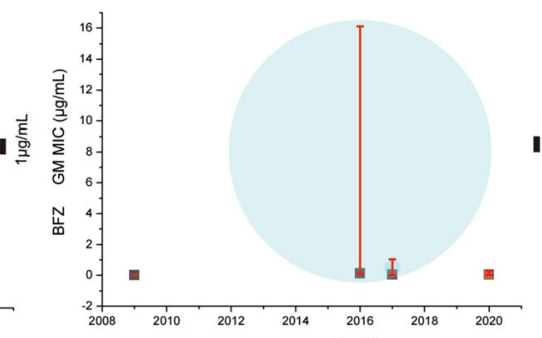

(B)

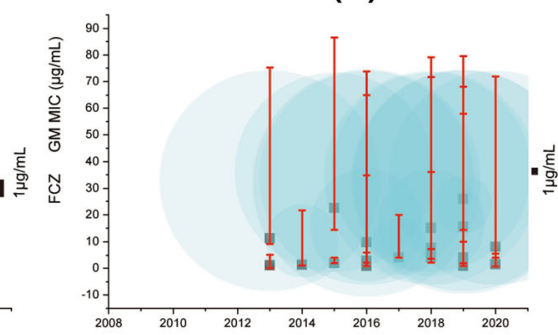

(E)

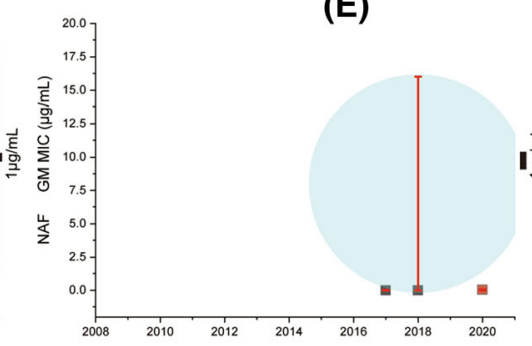

(H)

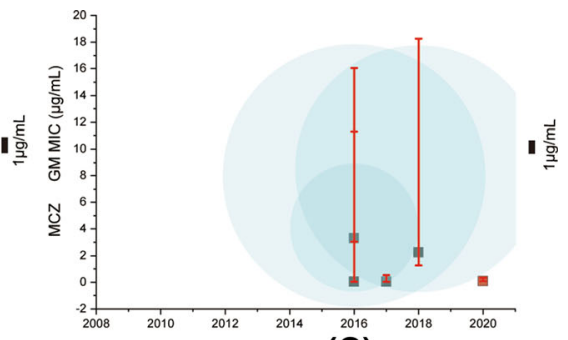

(C)

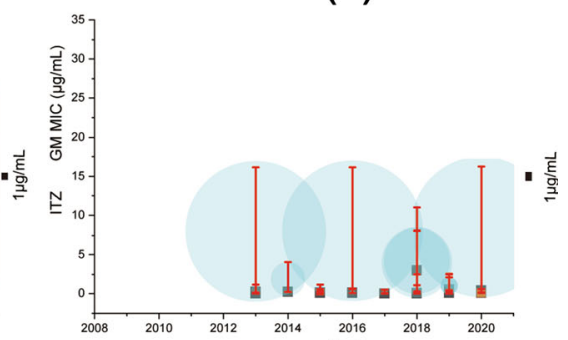

(F)

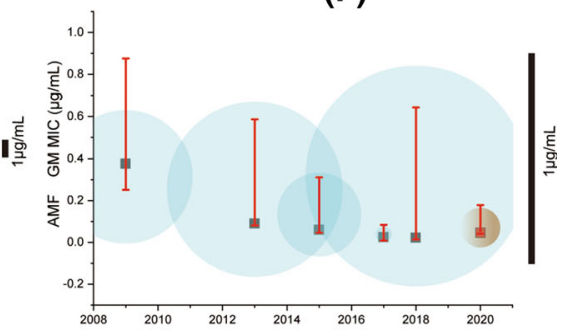

(l)
Fig. 4 Comparison of MIC values for nine antifungal drugs in T. rubrum strains from 2010 to 2020. (A-I). LLCZ, BFZ, MCZ, KTZ, ITZ, TBF, NAF, AMF. The spherical shape represents the

known to be sufficient for the distinction of siblings within the T. rubrum complex [27, 28]. In addition to 62 strains from our study, a global set of 71 sequences was found to be identical to T. rubrum haplotype H5 containing the type strain (CBS 392.58) [27]. The $100 \%$ match with phenotypic identification validates the IDs of older publications where no sequencing data are available. Five of the sequences, among which one from China, showed one SNP distance and clustered with T. rubrum H6 [27]. The ITS data support the earlier view of a global, largely clonal population range of MIC values for each study, the error bar is shown in red, and the black spot represents the GM value. Scale bar: $1 \mu \mathrm{g} / \mathrm{mL}$. (Color figure online)

structure with low levels of variation and no evidence of recombination [3]. The ITS marker is not epidemiologically associated with resistance, since $21 \mathrm{~T}$. rubrum strains with higher MICs recorded in previous studies belonged to the same population [18, 19, 53], as confirmed in our study (Fig. 1).

Judging from proposed breakpoints for dermatophytes [49, 53], i.e., $>2 \mu \mathrm{g} / \mathrm{mL}$ for FCZ and $>1 \mu \mathrm{g} /$ $\mathrm{mL}$ for ITZ, KTZ and TBF, the tested T. rubrum strains from China should be regarded as in vitro susceptible to all antifungal drugs. FCZ had a GM of 


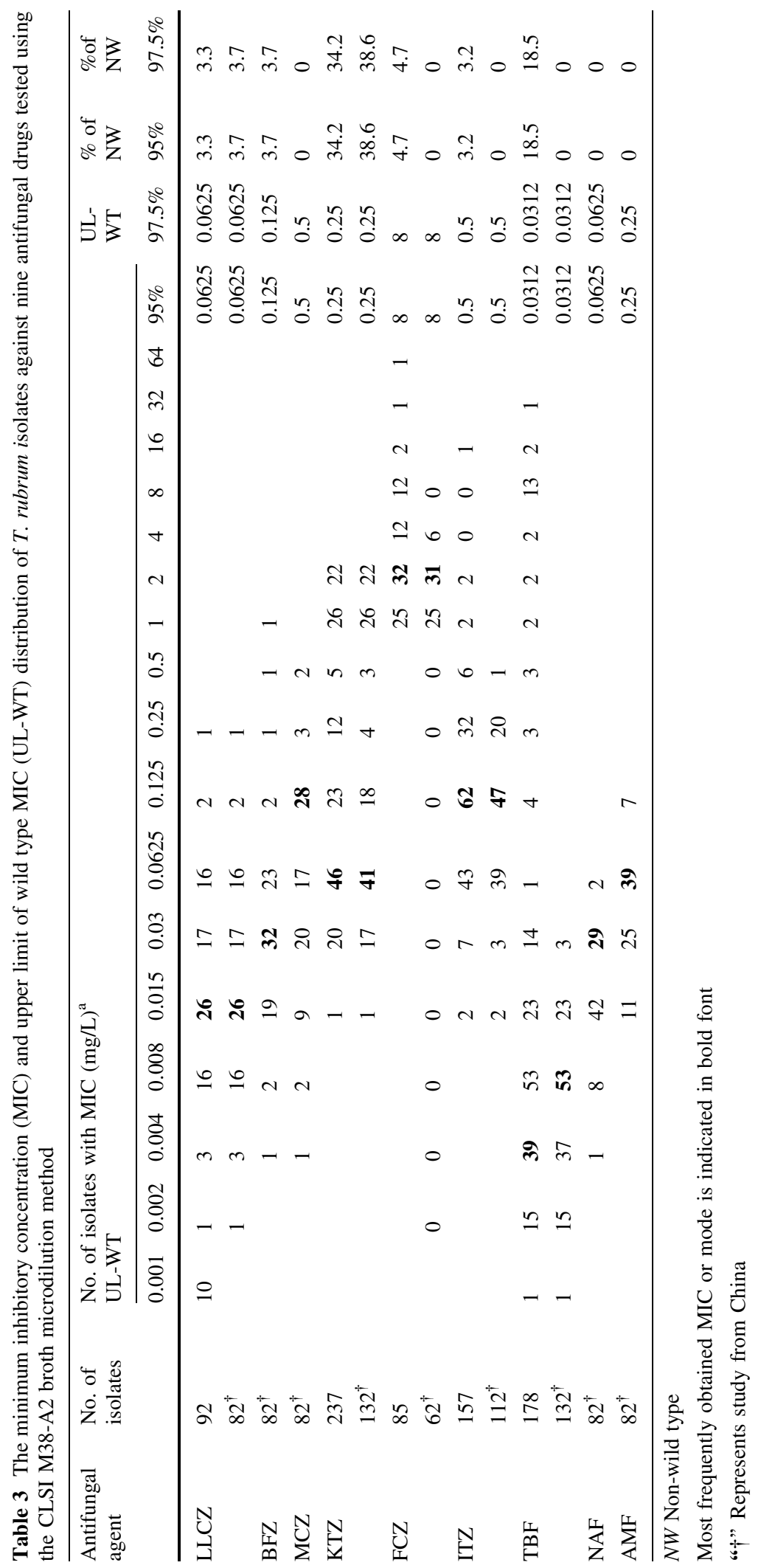


$1.6172 \mu \mathrm{g} / \mathrm{mL}$ in our study, ranging from 1 to $4 \mu \mathrm{g} /$ $\mathrm{mL}$. These values are significantly lower than usually found in filamentous fungi $(32 \mu \mathrm{g} / \mathrm{mL} ; 54]$, but the compound is known to be ineffective in dermatophytosis [49]. In our study, MIC values against ITZ (GM $0.12 \mu \mathrm{g} / \mathrm{mL}$, range $0.015-0.5 \mu \mathrm{g} / \mathrm{mL}$ ) were relatively high. In contrast, the older azole KTZ demonstrated moderate activity with lower MIC values (GM $0.05718 \mu \mathrm{g} / \mathrm{mL}$, range $0.015-0.25 \mu \mathrm{g} / \mathrm{mL})$. TBF showed strongest activity (GM $0.0068 \mu \mathrm{g} / \mathrm{mL}$ ) against T. rubrum in China. Comparing the activity of four drug categories based on chemistry and type of administration revealed statistically significant differences (Fig. 2B). Allylamines (TBF and NAF), which can be applied as topical or systemic agents, demonstrated stronger activity with lower MICs compared to remaining groups $(P<0.001)$. The topical azole category and the morpholines both had higher activity with lower MIC values in T. rubrum than the systemic azoles. In the terms of geography, differences between the Guizhou group and remaining Chinese provinces were not statistically significant for eight drugs. Only AMR had slightly higher MIC values in the Guizhou group than in remaining Chinese isolates. Since most strains (20/31) from Guizhou were isolated form toenails, all strains (31) in the China group were derived from foot skin; the reason for this difference needs further study. Nevertheless, the question of possible emerging resistance remains valid.

We therefore compared the MIC values in our study to similar studies in China as well as from other countries. Most of the English-language studies came from India (9/26) and Iran (6/26) (Table 2). Six additional studies from China were included. Although all studies were performed by following the CLSI M38-A2 protocol [29], small differences were observed in the protocols that we used, particularly in the incubation temperature: either $28^{\circ} \mathrm{C}$ (six studies) or micro-broth dilution requiring incubation at $33-35{ }^{\circ} \mathrm{C}$. It has been shown that $33{ }^{\circ} \mathrm{C}$ was the most suitable growth temperature for T. rubrum in terms of dry weight of mycelium and colony diameter [55]. The prevalence of T. rubrum involving protruding body parts is associated with an optimum growth below $35{ }^{\circ} \mathrm{C}$ [56]. The slow growth of the fungus requires reading of results after 5-7 days rather than after 72-96 h [57].

The most frequently studied drugs during the last decade globally are ITZ, FCZ, KTZ and TBF.
Although the MIC range of each study is relatively large, the GM value of most antifungal drugs is fixed in a certain range, indicating repeatability and reliability of the research results, which lays a foundation for the interpretation of ECV of T. rubrum for different antifungal drugs. Among the four drugs, the GM values of FCZ are scattered between studies (Fig. 3e), and MIC values are relatively high. In contrast, MIC values against TBF and ITZ were consistent, and GM values in different studies were basically at the same level (Fig. 3f, g). However, two studies on TBF from India published in 2019, which indicated that $T$. rubrum isolates that are highly resistant to $\mathrm{TBF}$, diverge significantly from remaining studies (Fig. 3g).

ECV analysis was performed simultaneously. We combined global distributions of MIC values from seven studies to distinguish between WT and non-WT populations and calculated upper limit of WT MIC (UL-WT) or epidemiological breakpoints. Since our study still could not totally fulfil the criteria of evaluation of ECV according to CLSI guidelines [58], we propose the UL-WT instead of ECV for $T$. rubrum of Chinese origin (Table 3 ).

FCZ was shown to have poor activity against $T$. rubrum, having the highest $97.5 \%$ UL-WT $(8 \mu \mathrm{g} / \mathrm{mL})$ agents. Different from T. mentagrophytes / T. interdigitale complex [59], the $97.5 \%$ UL-WT value of global T. rubrum for TBF was very low, i.e., $0.03 \mu \mathrm{g} /$ $\mathrm{mL}$. In contrast to China, the global group had a high percentage of isolates above UL-WT (global: 18.5\%, China: 0), which indicated that TBF may be still considered as the first choice for treatment in China. Naftifine, another allylamine drug, also has good activity against $T$. rubrum, with a low $97.5 \%$ UL-WT $(0.06 \mu \mathrm{g} / \mathrm{mL})$. In addition to these two drugs, $T$. rubrum and $T$. mentagrophytes/T. interdigitale showed similar UL-WT values for the azole and morpholines [59]. LLCZ, BFZ and AMF are good options to treat T. rubrum infection due to low $97.5 \%$ UL-WT with a low percentage of non-WT isolates. However, the amount of strains tested for the above three drugs is small, and more verification is required. Based on the classification and comparison of antifungal agents in this study, we preliminarily determined that topical TBF and NAF should be still recommended as first-line therapy against superficial skin infection caused by T. rubrum in China. Antifungal creams should remain without steroids, and an adequate treatment period can be estimated at 2 weeks 
after the rash disappears [54], avoiding potential development of resistance. The azole drugs KTZ and $\mathrm{MCZ}$, and particularly FCZ, are not recommended.

The limitation of this study is that the number of isolates is small; not every drug included MICs from the required minimum 100 unrelated isolates. However, our study preliminarily described and explored the UL-WT of T. rubrum, understood the trend of its sensitivity to a variety of antifungal agents and recommended first-line treatment for skin infection of this species in China. Regular surveillance of dermatophytes and antifungal susceptibility is recommended, since susceptibility profiles in general seem to be prone to change. At the same time, because of its highly conserved gene content, global prevalence and low virulence, $T$. rubrum may be a good choice as a research model for the mechanism of dermatophytes resistance.

Acknowledgements The authors thank Xu-Dong Wang from Institute for Molecules and Materials of Radboud University for his important contributions to the Graphic design. Special thanks to Weiwei Wu of Hainan Dermatology Hospital for sharing the original data.

Author Contributions YJ designed this project, carried out strains collection, phylogenetic tree construction, participated in the data analysis and drafted the manuscript. YS participated in the data analysis and revised the manuscript. WL performed DNA extraction and sequencing, carried out the literature search, carried out AFST tests. ZS and BZ carried out the statistical analysis. SA and AMS performed the antifungal susceptibility data analysis, contributed to the discussion and revision of the manuscript. ZW checked the AFST tests and provided the support of AFST methods. YJ, YS, RL, PEV and $\mathrm{SdH}$ participated in the design of the study, statistical analysis and manuscript revision and review. All authors read and approved the manuscript.

Funding This work was supported by Beijing Natural Science Foundation (No. 7194326), District Science Foundation Program (NSFC No. 81960368) from the National Natural Science Foundation of China and Science and Technology Fund project (No. gzwjkj 2019-1-114) from the Guizhou Provincial Health Commission.

\section{Compliance with Ethical Standards}

Competing interest The authors declare no conflicts of interest.

Ethical Approval The authors confirm that this material is original and has not been published in whole or in part elsewhere and that the manuscript is not currently being considered for publication in another journal and that all authors have been personally and actively involved in substantive work leading to the manuscript and will hold themselves jointly and individually responsible for its content.

Open Access This article is licensed under a Creative Commons Attribution 4.0 International License, which permits use, sharing, adaptation, distribution and reproduction in any medium or format, as long as you give appropriate credit to the original author(s) and the source, provide a link to the Creative Commons licence, and indicate if changes were made. The images or other third party material in this article are included in the article's Creative Commons licence, unless indicated otherwise in a credit line to the material. If material is not included in the article's Creative Commons licence and your intended use is not permitted by statutory regulation or exceeds the permitted use, you will need to obtain permission directly from the copyright holder. To view a copy of this licence, visit http://creativecommons.org/licenses/by/4.0/.

\section{References}

1. Hayette MP, Sacheli R. Dermatophytosis, trends in epidemiology and diagnostic approach. Curr Fung Infect Rep. 2015;9(3):1-16.

2. Ghannoum MA, Mukherjee PK, Warshaw EM, Evans S, Korman NJ, Tavakkol A. Molecular analysis of dermatophytes suggests spread of infection among household members. Cutis. 2013;91(5):237-45.

3. Persinoti GF, Martinez DA, Li W, Döğen A, Billmyre RB, Averette A, et al. Whole-genome analysis illustrates global clonal population structure of the ubiquitous dermatophyte pathogen Trichophyton rubrum. Genetics. 2018;208(4):1657-69.

4. Singh A, Masih A, Khurana A, Singh PK, Gupta M, Hagen F, et al. High terbinafine resistance in Trichophyton interdigitale isolates in Delhi, India harbouring mutations in the squalene epoxidase gene. Mycoses. 2018;61(7):477-84.

5. Rudramurthy SM, Shankarnarayan SA, Dogra S, Shaw D, Mushtaq K, Paul RA, et al. Mutation in the squalene epoxidase gene of Trichophyton interdigitale and Trichophyton rubrum associated with allylamine resistance. Antimicrob Agents Chemother. 2018;62(5):e02522-e2617.

6. Pathania S, Rudramurthy SM, Narang T, Saikia UN, Dogra S. A prospective study of the epidemiological and clinical patterns of recurrent dermatophytosis at a tertiary care hospital in India. Indian J Dermatol Venereol Leprol. 2018;84(6):678-84.

7. Nenoff P, Verma SB, Uhrlaß S, Burmester A, Gräser Y. A clarion call for preventing taxonomical errors of dermatophytes using the example of the novel Trichophyton mentagrophytes genotype VIII uniformly isolated in the Indian epidemic of superficial dermatophytosis. Mycoses. 2019;62(1):6-10. https://doi.org/10.1111/myc.12848.

8. Dahl MV, Grando SA. Chronic dermatophytosis: what is special about Trichophyton rubrum? Adv Dermatol. 1994;9:97-111. 
9. Lanternier F, Pathan S, Vincent QB, Liu L, Cypowyj S, Prando C, et al. Deep dermatophytosis and inherited CARD9 deficiency. N Engl J Med. 2013;369(18):1704-14.

10. Marconi VC, Kradin R, Marty FM, Hospenthal DR, Kotton CN. Disseminated dermatophytosis in a patient with hereditary hemochromatosis and hepatic cirrhosis: case report and review of the literature. Med Mycol. 2010;48(3):518-27.

11. Tsang P, Hopkins T, Jimenez-Lucho V. Deep dermatophytosis caused by Trichophyton rubrum in a patient with AIDS. J Am Acad Dermatol. 1996;34(6):1090-1.

12. Osborne CS, Hofbauer B, Favre B, Ryder NS. In vitro analysis of the ability of Trichophyton rubrum to become resistant to terbinafine. Antimicrob Agents Chemother. 2003;47(11):3634-6.

13. Hryncewicz-Gwóźdź A, Kalinowska K, Plomer-Niezgoda $\mathrm{E}$, Bielecki J, Jagielski T. Increase in resistance to fluconazole and itraconazole in Trichophyton rubrum clinical isolates by sequential passages in vitro under drug pressure. Mycopathologia. 2013;176(1-2):49-55.

14. Ghelardi E, Celandroni F, Gueye SA, Salvetti S, Senesi S, Bulgheroni A, et al. Potential of ergosterol synthesis inhibitors to cause resistance or cross-resistance in Trichophyton rubrum. Antimicrob Agents Chemother. 2014;58(5):2825-9.

15. Mukherjee PK, Leidich SD, Isham N, Leitner I, Ryder NS, Ghannoum MA. Clinical Trichophyton rubrum strain exhibiting primary resistance to terbinafine. Antimicrob Agents Chemother. 2003;47(1):82-6.

16. Schøsler L, Andersen LK, Arendrup MC, Sommerlund M. Recurrent terbinafine resistant Trichophyton rubrum infection in a child with congenital ichthyosis. Pediatr Dermatol. 2018;35(2):259-60.

17. Suzuki S, Mano Y, Furuya N, Fujitani K. Discovery of terbinafine low susceptibility Trichophyton rubrum strain in Japan. Biocontrol Science. 2018;23(3):151-4.

18. Salehi Z, Shams-Ghahfarokhi M, Razzaghi-Abyaneh M. Antifungal drug susceptibility profile of clinically important dermatophytes and determination of point mutations in terbinafine-resistant isolates. Eur J Clin Microbiol Infect Dis. 2018;37(10):1841-6.

19. Ebert A, Monod M, Salamin K, Burmester A, Uhrlaß S, Wiegand C, et al. Alarming India-wide phenomenon of antifungal resistance in dermatophytes: A multicentre study. Mycoses. 2020;63(7):717-28.

20. de Hoog GS, Guarro J, Gené J, Ahmed SA, AAhmed S, Vitale RG. Atlas of clinical fungi. 2019; Web-edition, Utrecht.

21. Jiang Y, Dukik K, Muñoz JF, Sigler L, Schwartz IS, Govender NP, et al. Phylogeny, ecology and taxonomy of systemic pathogens and their relatives in Ajellomycetaceae (Onygenales): Blastomyces, Emergomyces, Emmonsia Emmonsiellopsis. Fungal Divers. 2018;90(1):245-91.

22. White TJ, Bruns TD, Lee SB, Taylor JW. Amplification and sequencing of fungal ribosomal RNA genes for phylogenetics. In: Innis MA, Gelfand DH, Sninsky JJ, White TJ, editors. PCR protocols and applications: a laboratory manual. New York: Academic Press; 1990. p. 315-22.

23. Tamura K, Stecher G, Peterson D, Filipski A, Kumar S. MEGA6: molecular evolutionary genetics analysis version
6.0. Mol Biol Evol. 2013;30(12):2725-9. https://doi.org/10. 1093/molbev/mst197.

24. Ronquist F, Huelsenbeck JP. MrBayes 3: Bayesian phylogenetic inference under mixed models. Bioinformatics. 2003;19(12):1572-81.

25. Clinical and Laboratory Standards Institute. Reference method for broth dilution antifungal susceptibility testing of filamentous fungi. CLSI Standard M38, 3rd ed. 2017; Wayne, PA.

26. Turnidge J, Kahlmeter G, Kronvall G. Statistical characterization of bacterial wild-type MIC value distributions and the determination of epidemiological cut-off values. Clin Microbiol Infect. 2006;12:418-25.

27. Su H, Packeu A, Ahmed SA, Al-Hatmi AMS, Blechert O, Ilkit M, et al. Species distinction in the Trichophyton rubrum complex. J Clin Microbiol. 2019;57(9):e00352e419.

28. Packeu A, Stubbe D, Roesems S, Goens K, Van Rooij P, de Hoog S, Hendrickx M. Lineages within the Trichophyton rubrum complex. Mycopathologia. 2020;185(1):123-36. https://doi.org/10.1007/s11046-019-00386-z.

29. CLSI. Reference method for broth dilution antifungal susceptibility testing of filamentous fungi. 2nd ed. CLSI standard M38. Clinical and Laboratory Standard Institute; 2008; Wayne, PA.

30. Gao H, Chen J, Huang Y. In vitro susceptibility test of $T$. rubrum in the foot of Tianjin Public Security Special Police. Tianjin Med J. 2013;41(4):387-8.

31. He W, Gao Z, Xu H, Tan J, Cai Q, Yang H. Analysis of distribution and drug susceptibility of 82 strains of onychomycosis. Chin J Mycol. 2016;11(5):289-95.

32. Wu W, Wang Q, Gong J, Wan Z, Wang A, Li R. In vitro susceptibility testing of eight antifungal agents against pathogenic fungi isolated from superficial mycoses. Chin J Mycol. 2017;12(5):279-82.

33. Ding H. Epidemiology and in vitro susceptibility analysis of tinea pedis in Wuhan area. Jianghan University. 2018.

34. Li L, Zhang S, Li M, Gao L, Liu F, Lei D, et al. In vitro activities of antifungal drugs against 50 Trichophyton rubrum strains isolates. $\mathrm{J}$ Henan Med Colle. 2019;31(5):672-5.

35. Liu J, Liu X, Yu B, Hu X. Analysis on pathogenic characteristics of dermatophyte infection and in vitro drug susceptibility of 85 strains of dermatophyte. Chin J Mycol. 2019;14(06):351-6.

36. Schaller M, Borelli C, Berger U, Walker B, Schmidt S, Weindl G, et al. Susceptibility testing of amorolfine, bifonazole and ciclopiroxolamine against Trichophyton rubrum in an in vitro model of dermatophyte nail infection. Med Mycol. 2009;47(7):753-8.

37. Silva LB, de Oliveira DB, da Silva BV, de Souza RA, da Silva PR, Ferreira-Paim K, et al. Identification and antifungal susceptibility of fungi isolated from dermatomycoses. J Europ Acad Dermatol Venereol. 2013;28(5):633-40.

38. Wiederhold NP, Fothergill AW, McCarthy DI, Tavakkol A. Luliconazole demonstrates potent in vitro activity against dermatophytes recovered from patients with onychomycosis. Antimicrob Agents Chemother. 2014;58(6):3553-5.

39. Indira G. In vitro antifungal susceptibility testing of 5 antifungal agents against dermatophytic species by CLSI 
(M38-A) Micro Dilution Method. Clin Microbiol Open Access. 2014;3:145.

40. Tabata Y, Takei-Masuda N, Kubota N, Takahata S, Ohyama M, Kaneda K, et al. Characterization of antifungal activity and nail penetration of ME1111, a new antifungal agent for topical treatment of onychomycosis. Antimicrob Agents Chemother. 2015;60(2):1035-9.

41. Sowmya N, Appalaraju B, Srinivas CR, Surendran P. Antifungal susceptibility testing for dermatophytes isolated from clinical samples by broth dilution method in a tertiary care hospital. J Med Res. 2015;1(2):64-7.

42. Bhatia VK, Sharma PC. Determination of minimum inhibitory concentrations of itraconazole, terbinafine and ketoconazole against dermatophyte species by broth microdilution method. Indian J Med Microbiol. 2015;33(4):533-7.

43. Ansari S, Hedayati MT, Zomorodian K, Pakshir K, Badali $\mathrm{H}$, Rafiei A, et al. Molecular characterization and in vitro antifungal susceptibility of 316 clinical isolates of dermatophytes in Iran. Mycopathologia. 2016;181(1-2):89-95.

44. Sharifzadeh A, Shokri H, Khosravi AR. In vitro evaluation of antifungal susceptibility and keratinase, elastase, lipase and DNase activities of different dermatophyte species isolated from clinical specimens in Iran. Mycoses. 2016;59(11):710-9.

45. Baghi N, Shokohi T, Badali H, Makimura K, RezaeiMatehkolaei A, Abdollahi M, et al. In vitro activity of new azoles luliconazole and lanoconazole compared with ten other antifungal drugs against clinical dermatophyte isolates. Med Mycol. 2016;54(7):757-63.

46. Dabas Y, Xess I, Singh G, Pandey M, Meena S. Molecular identification and antifungal susceptibility patterns of clinical dermatophytes following CLSI and EUCAST guidelines. J Fungi (Basel). 2017;3(2):17.

47. Rezaei-Matehkolaei A, Khodavaisy S, Alshahni MM, Tamura T, Satoh K, Abastabar M, et al. In vitro antifungal activity of novel triazole efinaconazole and five comparators against dermatophyte isolates. Antimicrob Agents Chemother. 2018;62(5):e02423-e2517.

48. Poojary S, Miskeen A, Bagadia J, Jaiswal S, Uppuluri P. A study of in vitro antifungal susceptibility patterns of dermatophytic fungi at a tertiary care center in Western India. Indian J Dermatol. 2019;64(4):277-84.

49. Maurya VK, Kachhwaha D, Bora A, Khatri PK, Rathore L. Determination of antifungal minimum inhibitory concentration and its clinical correlation among treatment failure cases of dermatophytosis. J Family Med Prim Care. 2019;8(8):2577-81.
50. Salehi Z, Fatahi N, Taran M, Izadi A, Badali H, Hashemi SJ, et al. Comparison of in vitro antifungal activity of novel triazoles with available antifungal agents against dermatophyte species caused tinea pedis. J Mycol Med. 2020;30(2):100935.

51. Nenoff P, Verma SB, Vasani R, Burmester A, Hipler UC, Wittig F, et al. The current Indian epidemic of superficial dermatophytosis due to Trichophyton mentagrophytes-a molecular study. Mycoses. 2019;62(4):336-56.

52. Kano R, Kimura U, Kakurai M, Hiruma J, Kamata H, Suga $\mathrm{Y}$, et al. Trichophyton indotineae sp. nov.: a new highly terbinafine-resistant anthropophilic dermatophyte species. Mycopathologia. 2020.

53. Saunte DML, Hare RK, Jørgensen KM, Jørgensen R, Deleuran M, Zachariae CO, et al. Emerging terbinafine resistance in Trichophyton: Clinical characteristics, squalene epoxidase gene mutations, and a reliable EUCAST method for detection. Antimicrob Agents Chemother. 2019;63(10):e01126-e1219.

54. Pai V, Ganavalli A, Kikkeri NN. Antifungal resistance in dermatology. Indian J Dermatol. 2018;63(5):361-8.

55. Kadhim SK, Al-Janab JK, Al-Hamadani AH. In vitro, determination of optimal conditions of growth and proteolytic activity of clinical isolates of Trichophyton rubrum. J Contemp Med Sci. 2015;1(3):9-19.

56. Kanitakis J. Anatomy, histology and immunohistochemistry of normal human skin. Eur $J$ Dermatol. 2002;12(4):390-401.

57. Dogra S, Shaw D, Rudramurthy SM. Antifungal drug susceptibility testing of dermatophytes: Laboratory findings to clinical implications. Indian Dermatol Online $\mathrm{J}$. 2019;10(3):225-33.

58. Lockhart SR, Ghannoum MA, Alexander BD. Establishment and use of epidemiological cutoff values for molds and yeasts by use of the Clinical and Laboratory Standards Institute M57 standard. J Clin Microbiol. 2017;55(5):1262-8.

59. Shaw D, Singh S, Dogra S, Jayaraman J, Bhat R, Panda S, et al. MIC and upper limit of wild-type distribution for 13 antifungal agents against a Trichophyton mentagrophytesTrichophyton interdigitale complex of Indian origin. Antimicrob Agents Chemother. 2020;64(4):e01964-e2019.

Publisher's Note Springer Nature remains neutral with regard to jurisdictional claims in published maps and institutional affiliations. 